\title{
POPULARIZAÇÃO CIENTÍFICA E TECNOLÓGICA: EXPERIMENTOS DE FÍSICA ITINERANTES NO AMBIENTE ESCOLAR
}

\author{
SCIENTIFIC AND TECHNOLOGICAL POPULARIZATION: ITINERANT PHYSICS \\ EXPERIMENTS IN THE SCHOOL ENVIRONMENT
}

Marcio Carlos Just ${ }^{1}$

Leandro $\mathrm{Neckel}^{2}$

\begin{abstract}
RESUMO
O projeto Popularização Científica e Tecnológica é um projeto de extensão da Universidade do Extremo Sul Catarinense que busca levar até as escolas experimentos demonstrativos de física por meio de apresentações interativas. O projeto existe desde 2011 e surgiu da necessidade de tornar o ensino de física mais atrativo e próximo da realidade vivencial, no que se refere à compreensão da natureza por meio dos estudantes. Para isto, experimentos são desenvolvidos com o objetivo de apresentar, explorar e compreender fenômenos físicos naturais dentro das diferentes áreas da física (mecânica, térmica, óptica, elétrica, ondulatória e moderna). Os experimentos são apresentados em um formato de espetáculo, de forma a inspirar os estudantes que participam da apresentação. O projeto já atendeu 59 escolas até o momento e, durante a pandemia, realizou 4 apresentações por meio de transmissão via internet feita do laboratório de física experimental da Unesc (LaFiEx). Como resultado, percebe-se um aumento no interesse dos alunos das escolas atendidas por ciência e tecnologia e, ainda, uma conscientização de professores das próprias escolas em relação à importância da utilização de recursos experimentais para aprimoramento do processo de ensinoaprendizagem.
\end{abstract}

Palavras chave: divulgação científica. popularização da ciência. ensino de física. física itinerante

\begin{abstract}
The project PopularizaçãoCientífica e Tecnológica is an extension project of the Universidade do Extremo Sul Catarinense that seeks to bring demonstrative physics experiments to schools through interactive presentations. The project was originally created in 2011 and arose from the need to make physics teaching more palpable with regard to students' understanding of nature. For this, experiments are developed with the objective of presenting, exploring and understanding natural physical phenomena within the different areas of physics (mechanical, thermal, optical, electrical, wave and modern). The experiments are presented in a show format, in order to inspire the students who participate in the presentation. The project has already served 59 schools so far and, during the pandemic, it served 4 schools via internet transmission made by Unesc's experimental physics laboratory ( $\mathrm{LaFiEx})$. As a result, there is an increase in
\end{abstract}

\footnotetext{
${ }^{1}$ Universidade do Extremo Sul Catarinense - UNESC. mcj@ unesc.net. *autor para correspondência.

${ }^{2}$ Universidade do Extremo Sul Catarinense - UNESC. neckel.leandro@ unesc.net
} 
the interest of students from schools served by science and technology and, also, an awareness of teachers from the schools themselves regarding the importance of using experimental resources to improve the teaching-learning process.

Keywords: scientific divulgation. popularization of science. physics teaching. itinerant physics

\section{INTRODUÇÃO}

A "alfabetização científica prática" é uma prática que busca, em ambiente escolar formal ou informal, fazer com que um indivíduo se torne apto a solucionar problemas reais que afetam sua vida. Por outro lado, a "alfabetização científica cívica" é aquela que apresenta ao indivíduo em processo de alfabetização a ciência e seus problemas, preparando o mesmo para intervir com estes de forma mais bem embasada. Em outro nível, tem-se a "alfabetização científica cultural”, que define-se como a fração da ciência formal, disponibilizada para a população após uma transposição didática, com o objetivo de popularizar o mundo científico e divulgar o mesmo como uma façanha da humanidade (LORENZETTI; DELIZOICOV, 2001). De modo operacional, popularização científica pode ser definida como "um processo de transposição das idéias contidas em textos científicos para meios de comunicação populares" (MUELLER, 2002) ou conceituada como "uma ação cultural que, referenciada na dimensão reflexiva da comunicação e no diálogo entre diferentes, pauta suas ações respeitando a vida cotidiana e o universo simbólico do outro" (HUERGO, 2001)

A implantação de estratégias de divulgação científica eficazes para estudantes tem sido um desafio crescente. Por um lado, é necessário adequar métodos de divulgação de acordo com os conteúdos programáticos estabelecidos pelo ministério da educação. Por outro, é necessário tornar a abordagem mais dinâmica para que os estudantes percebam o ensino de ciências mais interessante e relevante para sua formação pessoal e profissional (RIBEIRO; CARVALHO, 2015). Neste contexto, a prática da popularização da ciência por vias fora da educação formal tem se mostrado valiosa para o estímulo e motivação dos estudantes.

A partir dos anos 80, tem-se observado o crescimento do número de políticas de incentivo à popularização científica no Brasil. Um reflexo desta ação foram 
principalmente a criação de centros e museus de ciência e uma maior ênfase de jornais e revistas relacionados à ciência e tecnologia. Uma prática mais recente foi a criação de projetos itinerantes de popularização científica, onde, a partir de instituições de ensino, o mundo científico é levado até à população. Dentre projetos como este, são possíveis citar o "Caminhão com Ciência", da universidade estadual de Santa Cruz, o projeto "Ciência Móvel”, do Espaço Ciência da Secretaria de Ciência e Tecnologia e Meio Ambiente de Pernambuco, o "Laboratório Móvel de Tecnologia.com.ciência" da Universidade Federal do Rio Grande do Sul, o "Museu itinerante de neurociências" da Universidade Federal do Rio de Janeiro, entre outros. As exposições itinerantes têm características similares às de mostras realizadas em centros de ciências e museus, com a diferença da comunidade não precisar se deslocar até o local do museu, facilitando, assim, o acesso aos projetos (WARTHA ET AL., 2015). Ainda, eventos como estes influenciam de forma positiva o processo de ensino-aprendizagem dentro do espaço escolar visto que são caracterizados como momentos onde discussões entre professores e alunos são mais abertas, com o objetivo de compreender melhor fenômenos ou conceitos (AMAZONAS ET. AL., 2017). Em geral, percebe-se que ações de popularização científica como estas motivam os estudantes e, ainda, os ajudam em suas atividades escolares (CORRÊA; MUNHÃO; FERNANDES DA SILVA, 2018).

A extensão, como uma prática institucionalizada, procura conhecer a realidade da comunidade de forma sistemática, produz conhecimento para a própria instituição e contribui para uma transformação nas atitudes e ações da comunidade. Dentro de cursos de licenciatura, projetos de extensão permitem o exercício da docência em espaços não formais e formais de ensino. Assim, esta prática, sendo associada à formação de professores, tem possibilitado aos estudantes de cursos de licenciaturas um espaço além daqueles oferecidos pelos próprios cursos ou das disciplinas de estágio supervisionado (SOUZA; SANTOS; GHIDINI, 2019). No contexto da comunidade, mais especificamente do ensino fundamental e médio, a extensão universitária tem como uma das propostas a aproximação entre as instituições de ensino básica e superior (ROTTA; RAZUCK; VIVEIRO, 2012). Desta aproximação surgem, dentro da área das ciências, demandas de atividades experimentais uma vez que, comumente, escolas da rede pública não estão devidamente equipadas com laboratórios didáticos. 
Tendo em vista tal demanda, o projeto "Popularização Científica e Tecnológica" teve como foco escolas públicas de ensino fundamental e médio que, por adesão, aceitaram receber a apresentação de um espetáculo, para a comunidade escolar, chamado "A ciência é um espetáculo". O espetáculo é constituído da apresentação de experimentos demonstrativos, apresentando fenômenos naturais, por meio de artefatos de simples construção, previamente confeccionados, que permitam aos participantes interagirem com os mesmos, provocando encantamento, estímulo e aprendizagens significativas. O projeto tem sido aprimorado e apresentado desde 2011 em escolas das cidades de Araranguá, Criciúma, Nova Veneza, Forquilhinha, Siderópolis, Treviso, Urussanga e Içara. Apresentações dos experimentos também foram feitas na Unesc para alunos de ensino fundamental e médio do Colégio Unesc (colégio de aplicação da Universidade do Extremo Sul Catarinense), para acadêmicos dos cursos de engenharia em aulas de reforço, para acadêmicos do curso de licenciatura em matemática da UNESC e em cursos de formação continuada para professores da rede municipal de Criciúma como proposta de ação metodológica nas aulas de ciências do ensino fundamental. Naturalmente, o projeto encontrou grande dificuldade em sua continuidade devido a pandemia do novo coronavírus Covid19 no ano de 2020. Entretanto, visto outros exemplos ao redor do Brasil que se remodelaram para atender a comunidade durante tal período (BARBOSA DA SILVA; ALMEIDA, 2020), o mesmo buscou se adaptar e manter o atendimento às escolas de forma virtual.

O presente documento apresenta de forma sintética o projeto supracitado, sua execução e seus resultados desde sua primeira versão.

\section{PROCEDIMENTOS METODOLÓGICOS}

O ensino da Física tem seu início no ensino fundamental, quando se realizam as apresentações iniciais desta ciência. Neste momento, esta área da ciência é apresentada como uma ciência experimental. Apesar de estar intrínseco no processo de ensino-aprendizagem, esse aspecto não era desenvolvido. O cenário do ensino da Física que se apresentava na época era fechado no mundo físico, desvinculado da realidade do educando e focado nas transposições apresentadas nos livros didáticos. A transmissão excessiva de conteúdos não corrobora para a criação de possibilidades de inserção dos 
alunos ao cotidiano, completamente dominado pela ciência e tecnologia. A Física é uma ciência que tem como base a confirmação de seus conceitos em observações experimentais, necessários para a validação da teoria. Porém, poucas escolas possuem laboratórios didáticos e aquelas que os têm, não são utilizados, quer seja por falta de condições estruturais, quer seja pela falta de habilidades do professor em atuar neste espaço.

Preocupados com o cenário regional, da educação formal, no ensino de ciências, principalmente na área da Física, o grupo de professores elaboraram o projeto de intervenção informal no processo formal de educação. O projeto nasceu em 2011 no CECIESC (Centro de Educação Ambiental da UNESC) e no curso de licenciatura em Ciências Biológicas. Preocupados com o ensino formal de ciências na escola básica, professores do curso buscavam alternativas para a melhoria do processo de ensinoaprendizagem. $\mathrm{O}$ formato era o de um espetáculo, onde o atrativo principal seria o encantamento produzido por fenômenos naturais forçados por artefatos construídos. $\mathrm{O}$ Projeto busca auxiliar a compreensão de conceitos e fenômenos físicos através da utilização de experimentos de baixo custo, realizados de forma interativa com os alunos do ensino básico. O apresentador do espetáculo deveria estabelecer um diálogo que envolvesse o artefato, o fenômeno e o modelo físico explicativo estabelecido. A tecnologia, a realidade vivencial e os modelos apresentados no ensino formal, eram os aspectos fundamentais para as escolhas para a construção dos artefatos. $\mathrm{O}$ foco fundamental do projeto era o de realizar a popularização científica e tecnológica, porém a ideia central era a intervenção no processo ensino aprendizagem, no sentido de mostrar, para o professor, a possibilidade do ensino experimental e sua importância para o ensino formal. Buscamos aproximar jovens estudantes da ciência e tecnologia, através de inovações metodológicas, mostrando o fenômeno experimental que está por trás dos conhecimentos que lhes são transmitidos em sala de aula. Nossa proposta é a de ampliar as atividades das aulas da educação formal e popularizar os conhecimentos construídos pela ciência e tecnologia, por meio de atividades itinerantes em escolas.

Nas duas últimas edições, o projeto voltou suas ações para o ensino médio e em escolas da região do extremo sul catarinense. Em sua totalidade, foram construídos trinta experimentos que contemplam os conteúdos do componente curricular de Física da escola média, mecânica, termologia, eletricidade e física moderna. Na fase de 
construção optou-se por experimentos que apresentavam elementos tecnológicos, aspecto contra intuitivos e que possuíam elevados valores didáticos. Os experimentos eram apresentados com um diálogo pré-elaborado pelos professores e bolsistas do projeto.

Os agendamentos das apresentações foram realizados por uma visita prévia dos monitores do projeto na escola. As escolas se mostraram solícitas e sinalizavam que iniciativas desse tipo eram importantes. As apresentações nas escolas eram realizadas, geralmente, em auditórios ou em salas maiores com as três séries do ensino médio juntas e duravam cerca de duas horas e meia. $\mathrm{O}$ apresentador interagia com os alunos fazendo perguntas e os chamavam para interagirem com os experimentos.

Com o objetivo de aumentar sua visibilidade, além de ter uma ferramenta de divulgação de seus resultados para a comunidade e, também, servir como portfólio, o projeto também contou com a elaboração de um website em formato de blog, acessível por meio do link http://www.pctunesc.com.br. Uma imagem da página principal do mesmo é apresentada na figura 1. Neste website foram disponibilizadas informações gerais sobre o projeto, assim como seu objetivo e resultados (locais de visitas, fotografias dos experimentos e da apresentação, entre outros). Além disto, o site também serviu como portal de divulgação científica, trazendo breves notícias sobre ciência e tecnologia.

Figura 1: Imagem da página principal do website do projeto.

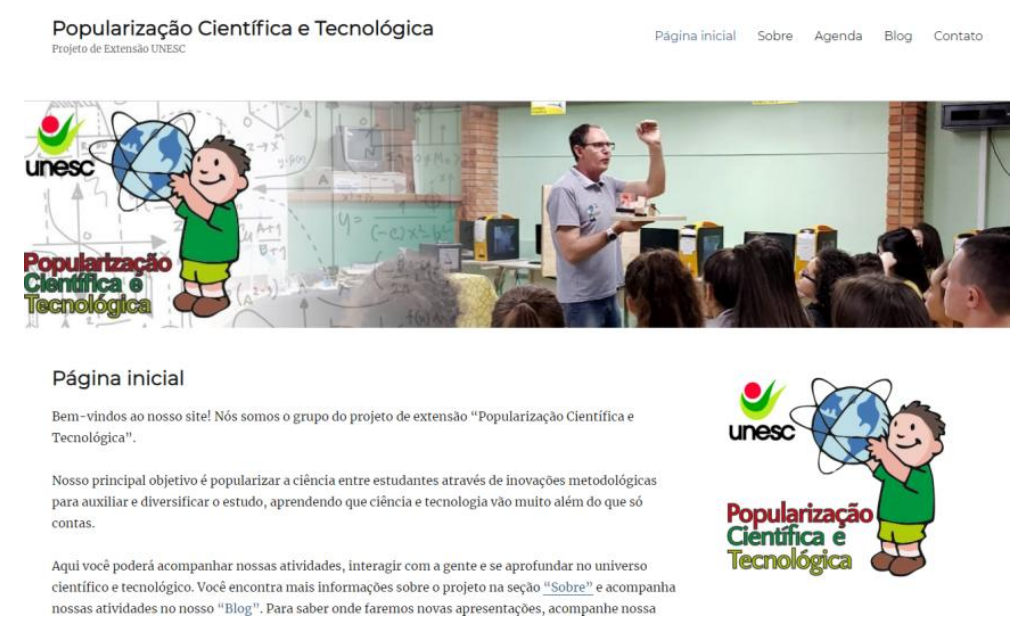

Fonte: http://www.pctunesc.com.br 


\section{DESENVOLVIMENTO}

No início da execução do projeto, o foco do projeto era o ensino fundamental, que é realizado pela rede pública municipal. No primeiro ano do projeto foram realizadas formações para professores de ciências da secretaria municipal de Criciúma, devido às diversas apresentações realizadas e o sucesso da metodologia apresentada. Também foi apresentada a metodologia nos cursos de formação de professores da universidade local.

$\mathrm{Na}$ sua totalidade, desde 2011, o projeto já realizou cinquenta e nove intervenções. Na sua última edição o projeto Popularização Científica e Tecnológica realizou vinte e uma apresentações, vinte em escolas públicas do ensino médio da região sul catarinense e uma apresentação para a primeira fase do curso de Licenciatura em Física da universidade local apresentando a metodologia para futuros professores de Física. Em algumas escolas o projeto realizou duas apresentações em turnos diferenciados, por solicitação dos professores de Física, que apoiam a iniciativa. A metodologia do projeto de realização de atividades experimentais, sem a necessidade do uso do laboratório formal e os experimentos construídos são utilizados nas disciplinas de Prática de ensino I, II e II do curso de licenciatura em Física, reforçando a necessidade de despertar no acadêmico a necessidade da utilização dos experimentos no processo ensino aprendizagem em Física.

Em 2016 a metodologia e os experimentos foram apresentados para a comunidade através da elaboração e publicação de um livro da Ediunesc, com o título “Atividades Experimentais em Sequências Didáticas ISBN: 978-85-8410-046-0”. A elaboração deste material contou com as parcerias dos alunos concluintes e dos professores do curso de Física - Licenciatura do PARFOR - UNESC. A parceria com o programa PARFOR permitiu que se entregasse gratuitamente, dois exemplares do livro, para todos os professores de Física e bibliotecas das escolas públicas da rede estadual que compõem a 20a CRE (Coordenadoria Regional de Educação de Santa Catarina).

$\mathrm{Na}$ maioria das escolas encontramos receptividade dos estudantes, professores e coordenadores na metodologia e no projeto. A percepção era de que cumpria o objetivo, mas sinalizavam que o tempo de aplicação deveria ser estendido, porém nossa 
intenção não era o de fazer um processo ensino aprendizagem formal, e sim popularizar a Tecnologia e a Ciência e mostrar que a utilização de atividades experimentais no ensino não, necessariamente, necessita de um laboratório estruturado construído, mas que pode ser diversificado e realizado em sala de aula com pequenas adaptações e a construção de artefatos pelo professor ou pelos estudantes. Alguns experimentos montados para apresentação o momento da interação dos alunos com os experimentos são demonstrados pela figura 2 (a) e (b).

Figura 2: Apresentação das atividades do projeto Popularização Científica e Tecnológica no Colégio Luiz Tramontin de Forquilhinha, SC. (a) Alguns experimentos apresentados na ocasião. (b) Momento da interação dos alunos com os experimentos

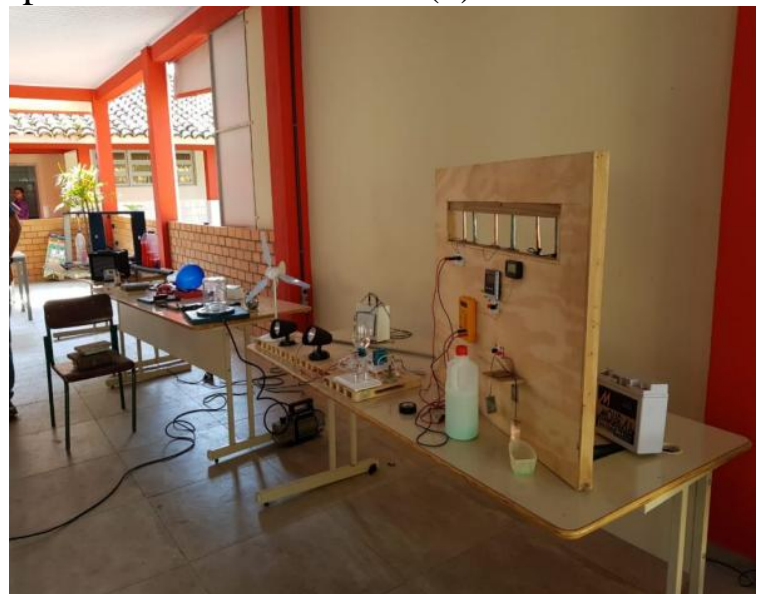

(a)

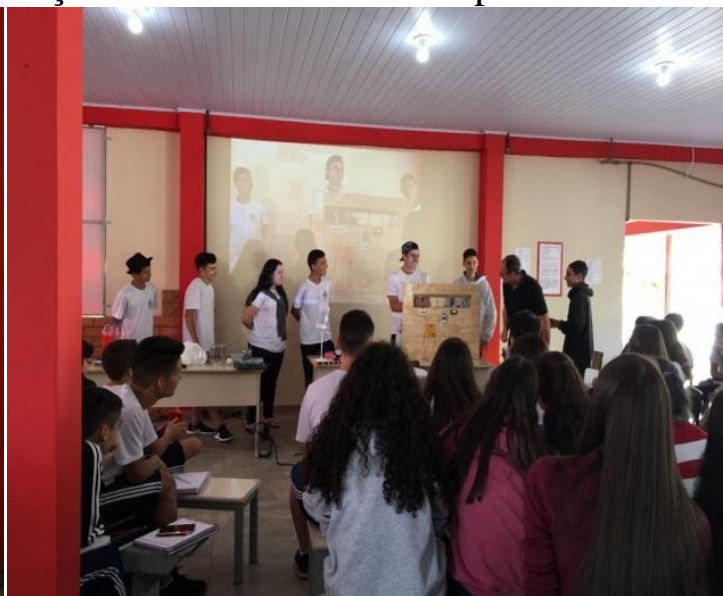

(b)

Fonte: elaborada pelo autor

Em tempos de pandemia, onde era impossível a aplicação do projeto do formato presencial, foram realizadas quatro apresentações, transmitidas do laboratório de Física da Unesc (LAFIEX), utilizando o aplicativo Google Meet da plataforma Google por meio do aplicativo gratuito para transmissões OBS. Os experimentos apresentados neste formato foram similares àqueles desenvolvidos nas intervenções presenciais. A metodologia foi também bem recebida pelas escolas, professores e estudantes que foram atendidos.

\section{CONSIDERAÇÕES FINAIS}


A extensão, como prática institucionalizada, nos permitiu vivenciar o processo ensino aprendizagem nas escolas públicas da região do extremo sul catarinense. Apesar dos objetivos do projeto de extensão não serem os de avaliar o processo de ensino aprendizagem, ele nos possibilitou obter conclusões, através das visitas constantes, das interações e dos diálogos conceituais proporcionados com os estudantes no transcorrer das 59 apresentações, desde 2011. Os diálogos desenvolvidos através do projeto eram conceituais uma vez que, tal abordagem, é importante para a apropriação do mundo Físico. Entretanto, corriqueiramente, tais intervenções eram fragilizadas pelo desconhecimento dos assuntos, o que revela uma ineficácia do ensino sob as condições atuais. A apropriação desse arsenal de conhecimentos, cada vez mais se torna fundamental e necessário para se guiar no mundo vivencial, totalmente dominado por processos tecnológicos que envolvem estes conceitos. Assim, na quase totalidade das apresentações os estudantes se mostraram interessados e encantados quando a natureza se apresentava, mesmo que de maneira simples, por meio dos experimentos construídos. Este encantamento, produzido por esta metodologia, é importante para melhoria do processo de ensino-aprendizagem.

$\mathrm{Na}$ percepção dos autores, a conscientização quanto a importância do uso desses recursos (experimentos, computadores, projetores, laboratórios de informática) tem aumentado entre os professores de ciências das escolas. Entretanto, projetos com experimentos deste tipo são trabalhosos uma vez que necessitam de elaboração, construção, transporte, a montagem, a apresentação e, para alguns destes passos, o processo reverso. De qualquer forma, ao final das apresentações o resultado é compensador, quando o apresentador fica, normalmente, rodeado de alunos interessados, fazendo perguntas e solicitando informações e sugestões para poderem utilizar nas suas respectivas Feiras de Ciências.

Como a universidade possui um curso de licenciatura em Física, a execução do projeto trouxe muitas contribuições e possibilidades de intervenção dos acadêmicos nas escolas da região. Ainda, os professores que lecionam no curso também percebem que metodologia desenvolvida e aplicada no projeto contribui para a compreensão do mundo científico e tecnológico, conciliando a vivência teórica de sala de aula com as experiências observadas durante as apresentações. Por fim, mostra a importância dos 
espaços informais de educação, principalmente na Popularização da Ciência e da Tecnologia.

\section{AGRADECIMENTOS}

Os autores gostariam de agradecer à Diretoria de Extensão, Cultura e Ações Comunitárias da Universidade do Extremo Sul Catarinense pelo apoio dado ao projeto e às Secretarias Municipais e Estadual de Educação por acreditarem na diferença que o mesmo poderia fazer na formação dos estudantes, permitindo que o projeto fosse executado nas diferentes escolas atendidas.

\section{FONTE DE FINANCIAMENTO}

Diretoria de Extensão, Cultura e Ações Comunitárias da Universidade do Extremo Sul Catarinense

\section{REFERÊNCIAS}

AMAZONAS, Márcio;PINHEIRO, Thayany;LYRA, Sergio, SACRAMENTA, Haklla.; Física itinerante: resultados de um projeto de divulgação científica no Amazonas. XI ENPEC - Encontro nacional de pesquisa em educação de ciências. 03 a 06 de Julho de 2017.

BARBOSA DA SILVA, Ítallo; ALMEIDA, Alves Almeira; A utilização de plataformas digitais para a popularização da ciência. Conedu, VII Congresso Nacional de Educação, 15 a 17 de Outubro, 2020.

WARTHA, Edson José et al.; Divulgação e popularização científica no projeto "Ciência sobre Rodas" como espaço educativo. Revista do Ensino de Ciências e Matemática, V6 N3, 2015.

CORRÊA, Hamilton Perez Soares; MUNHÃO, Marcos Vinicius Santos; FERNANDES DA SILVA, Renan Aryel; Projeto de desenvolvimento de equipamentos de popularização científica.Anais do IX seminário regional de extensão universitária da região centro oeste. 20 a 22 de Agosto de 2018.

HUERGO, Jorge.; La popularización, mediación y negociación de significados; SeminarioLatinoamericanoEstrategias para laFormación de Popularizadores em Ciencia y TecnologíaRed-POP,ConoSur. La Plata, 14 al 17 de mayo de 2001. 
LORENZETTI, Leonir; DELIZOICOV, Demétrio.Alfabetização Científica no Contexto das Séries Iniciais, Ensaio - Pesquisa em Educação de Ciências, V03 N1, 2001

MUELLER, Suzana Pinheiro Machado.Popularização do Conhecimento Ciêntifico, DataGramaZero - Revista de Ciência da Informação, V3 N2, 2002

RIBEIRO, Daniel, SIMEÃO CARVALHO, Paulo.; O impacto de técnicas de divulgação itinerante de ciência na promoção do interesse pela física. Interacções, No39, 2015

ROTTA, Jeane Cristina Gomes; RAZUCK, Renata Cardoso de Sá Ribeiro; VIVEIRO, Alessandra Aparecida.Um projeto de extensão universitária como perspectiva para a realização das práticas de ensino em um curso de formação de professores. Ensino superior: Inovação e Qualidade na docência, CIDU, Atas do congresso, 2012.

PANTANO SOUZA, Gahelyka Aghta; SANTOS, Bianca Martins; GHIDINI, André Ricardo. Experiências da extensão universitária na formação de professores de ciências. ScientiaNaturalis, V1 N5, 2019. 